\title{
Uncomplicated Stereotactic and Open Neurosurgical Procedures in Patients with Factor VII Deficiency
}

\author{
Stephen E. Doran, M.D., Thomas R. Henry, M.D., Paula L. Bockenstedt, M.D., and \\ Donald A. Ross, M.D. \\ University of Michigan Medical Center, Ann Arbor
}

Doran SE, Henry TR, Bockenstedt PL, Ross DA. Uncomplicated stereotactic and open neurosurgical procedures in patients with factor VII deficiency. Surg Neurol 1994;42:79-82.

Factor VII deficiency is characterized by epistaxis, bruising, hemarthrosis, mennorrhagia, gastrointestinal bleeding, hematuria, and intracranial hemorrhage during infancy. Causes of acquired factor VII deficiency include liver disease, Vitamin $K$ deficiency, and warfarin administration. Congenital factor VII deficiency is an autosomal recessive disorder, with the homozygotes having a severe deficiency and the hetereozygotes a moderate deficiency of factor VII. Orthopedic, gynecological, cardiothoracic, and abdominal surgical procedures have been successfully performed in patients with factor VII deficiency both with and without factor VII replacement. We present two patients with moderate and moderately severe factor VII deficiency who successfully underwent intracranial procedures using plasma during the perioperative period for factor VII replacement. One patient successfully underwent stereotactic placement of mesial temporal lobe depth electrodes and subdural strip electrodes followed by anterior temporal lobectomy for medically refractory seizures. The second patient successfully underwent craniotomy for an olfactory groove meningioma. No bleeding complications were encountered with any of the three intracranial procedures performed. These cases represent the first reported cases of successful intracranial procedures in patients with factor VII deficiency, other than shunting procedures performed for intraventricular hemorrhage during infancy.

KEY WORDS: Craniotomy; Factor VII deficiency; Neurosurgery; Stereotactic

Factor VII is a vitamin K-dependent protein synthesized by the liver. As part of the extrinsic clotting pathway, factor VII complexes with tissue factor, and in the

Address reprint requests to: Stephen E. Doran, M.D., Section of Neurosurgery, University of Michigan Medical Center, 1500 E. Medical Center Drive, Ann Arbor, MI 48105-0338.

Received November 12, 1993; accepted January 6, 1994.

(c) 1994 by Elsevier Science Inc. presence of calcium, activates factor IX [13]. Symptoms of factor VII deficiency include recurrent epistaxis, easy bruising, hemarthrosis, menorrhagia, gastrointestinal bleeding, hematuria, and intracranial hemorrhage $[1,6,8,9,10,14]$. Factor VII deficiency is either congenital or acquired. Causes of acquired factor VII deficiency include liver disease, Vitamin $\mathrm{K}$ deficiency, and warfarin administration [8]. Congenital factor VII deficiency is inherited in an autosomal recessive pattern, with homozygotes having severe deficiency $(0 \%-25 \%)$ and heterozygotes having a moderate deficiency $(25 \%-$ $75 \%$ ) of factor VII [8]. In general, only those with severe deficiency are symptomatic, although there are marked variations in bleeding tendencies among patients with similar degrees of deficiency $[6,8,9,17]$.

Several case reports describe surgery in the presence of factor VII deficiency. Patients with severe factor VII deficiency have successfully undergone orthopedic, gynecological, cardiothoracic, and abdominal procedures $[2,3,5,7,8,15,18]$. During the perioperative period, factor VII concentrate and/or plasma have been used to maintain hemostasis. However, successful surgery without factor VII replacement has also been reported $[6,8,12,17\}$.

Neurosurgical procedures require the most meticulous hemostatic control as even a small amount of bleeding, especially intracranially, is not tolerated without significant morbidity to the patient. Stereotactic procedures present an even greater challenge to the hemostatic mechanisms as little or no opportunity exists to control unexpected hemorrhage. We present two patients with factor VII deficiency who successfully underwent a total of three intracranial neurosurgical procedures using plasma for factor VII replacement.

\section{Case 1}

This patient is a 31 -year-old, right-handed man with complex partial seizures refractory to medical therapy. Depth and subdural strip electrodes were indicated as noninvasive methods of localizing a seizure focus were 
nondiagnostic. Bilateral mesial temporal depth electrodes and bilateral temporal neocortical subdural strip electrodes were recommended. However, during routine preoperative laboratory evaluation, the patient's prothrombin time (PT) was found to be 15.8 seconds, 1.3 times control. Liver function and other coagulation studies, including platelet count, partial thromboplastin time (PTT), and bleeding time were within normal limits. This elevation of the prothrombin time corrected in vitro upon addition of $50 \%$ normal pooled plasma.

The patient denied any prior bleeding problems, such as epistaxis, gingival bleeding, easy bruisability, or hemarthrosis. Prior surgical procedures including tonsillectomy as a child and tooth extractions as an adult were not complicated by hemorrhage.

The patient then received parenteral Vitamin K supplementation for 1 week, but the PT remained elevated. Factor VII level was then measured at $46 \%$ of expected level, with $80 \%$ to $150 \%$ considered within normal limits.

The patient first underwent placement of bilateral mesial temporal depth electrodes and bilateral temporal neocortical subdural strip electrodes. The patient's factor VII deficiency was managed with plasma, both fresh frozen and single donor. The patient received a total dose of $10 \mathrm{cc} / \mathrm{kg}$ with three units (one unit $=$ approximately $200 \mathrm{cc}$ to $250 \mathrm{cc}$ ) transfused immediately prior to surgical incision and three units transfused intraoperatively. No intraoperative bleeding difficulties were encountered.

Postoperatively, the patient received one unit of single donor or fresh frozen plasma every 8 hours until the fourth postoperative day. Meanwhile, seizure monitoring proceeded uneventfully. Daily PT was measured. However, on postoperative day 8 , the PT rose above 15 , and he then received one unit of plasma every 12 hours until the subdural strip and temporal lobe depth electrodes were removed at the bedside uneventfully.

At a later date, the patient was readmitted to the hospital for a left anterior temporal lobectomy, which was done with the patient awake. Upon arrival to the operating room, he was immediately given three units of plasma, followed by another three transfused throughout the duration of the case. No intraoperative bleeding difficulties were encountered. Postoperatively, he was given one unit of plasma every 12 hours until postoperative day 3 . He was discharged on the fourth postoperative day. He has remained seizure-free for 1 year, and no infectious complications of transfusion have developed.

\section{Case 2}

A 66-year-old woman presented with a 1-year history of personality changes, 3 -month history of urinary inconti- nence, and a generalized tonic-clonic seizure. Computed tomography (CT) and magnetic resonance imaging (MRI) scans revealed a probable olfactory groove meningioma.

Routine preoperative workup revealed an elevated PT of 14.9 (ratio of 1.2). Bleeding time, platelet count, PTT, fibrinogen, and fibrin split products were within normal limits. Mixing studies revealed the abnormal PT corrected in vitro upon addition of $50 \%$ normal pooled plasma. Factor VII level was $27 \%$ (normal $=80 \%-$ $150 \%)$.

The patient denied any prior bleeding problems. She had previously undergone two cesarean sections, an appendectomy, and a hysterectomy without any complications.

Preoperatively the patient was given $10 \mathrm{cc} / \mathrm{kg}$ of plasma (four units). She underwent bifrontal craniotomy for removal of an olfactory groove meningioma, with fascia lata and pericranial grafts. No unexpected bleeding was encountered. Three units of plasma and one unit of packed red blood cells were given intraoperatively. Postoperatively, her neurologic status remained unchanged.

She was transfused with one unit of plasma every 12 hours until the fourth postoperative day. An additional three units of packed red blood cells were also given during the immediate 48 hours postoperative. No bleeding complications were encountered, and the patient made a full recovery. No infectious complications of transfusion have developed.

\section{Discussion}

Management of factor VII deficiency in surgical candidates is controversial. Given the variable bleeding tendencies among patients with severe deficiency, it is not surprising that surgical procedures have been safely performed without replacement therapy $[6,8,12,17]$. This observation led Yorke and Mant to recommend that routine preoperative replacement therapy is not justified, and transfusions should be given only if bleeding problems arise [17]. However, for severe deficiencies, most authors recommend replacement therapy at least during and immediately after surgery. Strauss suggested transfusion of $10 \mathrm{~mL}$ of plasma per kg immediately before major surgical procedures and $4 \mathrm{~mL} / \mathrm{kg}$ every 4 hours through the first postoperative day [15]. Zimmerman et al recommended transfusion of 10 to 15 units of factor VII concentrate per $\mathrm{kg}$ of body weight every 6 hours through the first three postoperative days [19]. Marder and Shulman recommended sufficient plasma transfusions to produce a factor VII level of $10 \%$ to $20 \%$ at the time of surgery and for several days postoperatively [8]. Obviously, replacement therapy is 
not without hazard, with at least one reported case of antibody evidence of seroconversion to the human immunodeficiency virus as a result of replacement therapy for factor VII deficiency in a patient undergoing hip replacement [2].

The two cases presented in this article represent moderate (patient \#1, factor VII $=46 \%$ ) and moderately severe (patient \#2, factor VII $=28 \%$ ) examples of factor VII deficiency. In the absence of hepatobiliary disease, warfarin treatment, and lack of response to Vitamin $K$ therapy in patient $\# 1$, it is probable that both of these patients are heterozygous for congenital factory VII deficiency. Therefore, it is also likely that most surgical procedures could have been performed successfully without replacement therapy.

However, intracranial procedures demand meticulous hemostasis. Minimal amounts of unexpected hemorrhage can result in significant morbidity and mortality. Both cases illustrate situations where hemostasis is challenged beyond other intracranial procedures. The first patient successfully underwent stereotactic placement of mesial temporal lobe depth electrodes and subdural temporal strip electrodes. This procedure is performed through four small (approximately $10 \mathrm{~mm}$ ) trephines, two each placed symmetrically in the temporal and occipital regions. Intracranial hemostasis can be surgically maintained only at the dural and pial surfaces immediately beneath the trephine. The body's natural hemostatic mechanisms provide the only other barrier to uncontrolled hemorrhage within the substance of the brain or on the surface of the temporal lobe inaccessible through the small opening in the skull. The second patient underwent uneventful removal of an olfactory groove meningioma, a tumor that frequently is vascular and occasionally requires transfusion of blood in patients without a coagulopathy.

Given the grave consequences of unexpected intracranial hemorrhage, we elected to transfuse our patients with plasma for replacement of their factor VII deficiency. Immediately preoperarively $10 \mathrm{cc}$ of plasma per $\mathrm{kg}$ of body weight was given, followed by one unit of plasma every 8 to 12 hours postoperatively through at least the third postoperative day and as long as 12 days postoperatively in patient \#1 while intracranial recording electrodes were in place.

These two cases illustrate another controversial issue. As neither patient had a history of a bleeding disorder and were both otherwise healthy, one may question the necessity of obtaining a preoperative coagulation profile in these patients. After reviewing the medical records of 3782 healthy patients scheduled to undergo an elective surgical procedure, Narr et al concluded that routine preoperative screening tests were not indicated for healthy subjects under age 40 [11]. Suchman and
Griner suggest that obtaining PT and PTT preoperatively is not indicated in the absence of either historical or physical evidence of a coagulopathy [16]. However, preoperative coagulation screening may be justified in the present patients for several reasons. In case \#1, the patient had been on chronic phenytoin therapy, which has known hepatotoxic properties [4]. In case \#2, the patient was 66 years old. According to Narr, a patient older than 60 years is an indication for a more extensive preoperative laboratory workup [11]. One may also argue that any intracranial procedure is an indication for routine preoperative coagulation profile given the grave consequences of uncontrolled hemorrhage.

These two cases represent, to the best of our knowledge, the only published cases of intracranial procedures performed on patients with factor VII deficiency other than shunting procedures after intracranial hemorrhage in childhood $[1,14]$. Our experience indicates that patients with moderate to moderately severe factor VII deficiency can safely undergo intracranial procedures using plasma transfusions during the perioperative period.

\section{References}

1. Bedizel M, Albers R. Hereditary factor VII in newborns. Clin Pediatr 1983;22:774-5.

2. Briet $E$, Onvlee $G$. Hip surgery in a patient with severe factor VII deficiency. Haemostasis 1987;17:273-7.

3. Gagliardi C, D'Avino R, Stassano P, Musumeci A, Spampinato N. Open heart surgery with factor VII deficiency. J Cardiovasc Surg 1983;24:172-4.

4. Gilman, AG. Goodman and Gilman's the pharmacological basis of therapeutics. 8th ed. Elmsford: Pergamon Press Inc., $1990 ; 441-3$.

5. Greene WB, McMillan CW. Surgery for scoliosis in congenital factor VII deficiency. Am J Dis Child 1982;136:411-3.

6. Hall CA, Rapaport SI, Ames SB, DeGroot JA. A clinical and family study of hereditary proconvertin (factor VII) deficiency. Am J Med 1964;37:172-81.

7. Kuzel T, Green D, Stulberg SD, Baron J. Arthropathy and surgery in congenital factor VII deficiency. Am J Med 1988;84:771-4.

8. Marder VJ, Shulman NR. Clinical aspects of congenital factor VII deficiency. Am J Med 1964;37:182-93.

9. Mariani G, Mazzucconi MG. Factor VII congenital deficiency. Clinical picture and classification of the varients. Haemostasis 1983;13:169-77.

10. Matthay KK, Koerper MA, Ablin AR. Intracranial hemorrhage in congenital factor VII deficiency. J Pediatr 1979;94:413-5.

11. Narr BJ, Hansen TR, Warner MA. Preoperative laboratory screening in healthy Mayo patients: cost-effective elimination of tests and unchanged outcomes. Mayo Clin Proc 1991;66:155-9.

12. Niedringhaus RD, Aas J, Sanford JB. Congenital factor VII deficiency: safety of surgery without preoperative transfusion. Minn Med 1979;62:791-2.

13. Osterud B, Rapaport SI. Activation of factor IX by the reaction product of tissue factor and factor VII: additional pathway for 
initiating blood coagulation. Proc Natl Acad Sci USA $1977 ; 74: 5260-64$

14. Ragni MV, Lewis JH, Spero JA, Hasiba U. Factor VII deficiency. Am J Hematol 1981;10:79-88.

15. Strauss HS. Surgery in parients with congenital factor VII deficiency (congenital hypoproconvertinemia). Experience with one case and review of the literature. Blood 1965;25:325-34.

16. Suchman AL, Griner PF. Diagnostic use of the activated partial thromboplastin time and prothrombin time. Ann Intern Med $1986 ; 104: 810-6$.
17. Yorke AJ, Mant MJ. Factor VII deficiency and surgery. Is preoperative replacement therapy necessary? JAMA 1977; 238:424-5.

18. Zacharski LR, Delprete SA, Kisiel W, Hunt J, Cornell CJ, Marrin CA. Atherosclerosis and coronary bypass surgery in hereditary factor VII deficiency. Am J Med 1988;84:955-9.

19. Zimmerman R, Ehlers G, Ehlers W, et al. Congenital factor VII deficiency: a report of four new cases. Blut 1979;38:119-25. 